\title{
DEFINING, REPORTING, AND MONITORING NEAR-FALLS IN OLDER ADULTS: A SCOPING REVIEW PROTOCOL
}

\section{Definição, registro e monitoramento de quase-quedas em idosos: protocolo de revisão de escopo}

\author{
Carina Junqueira Cervato ${ }^{\mathrm{a}}$ (D), Giselle Layse Andrade Buarque ${ }^{\mathrm{D}}$, Katie Robinson ${ }^{\mathrm{b}}$ (),

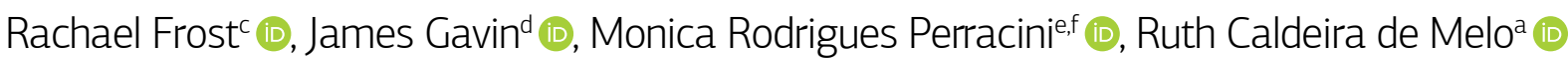

INTRODUCTION: In addition to traditional risk factors for falls (e.g., reduced muscle strength, polypharmacy, and poor vision), researchers have been investigating whether other factors, such as near-falls, can be identified to allow early intervention and prevention. A near-fall can be defined as a slip, trip, or loss of balance that would result in a fall if adequate recovery mechanisms were not activated. Despite the increasing interest in near-falls, there is no consensus about the definition, reporting methods, and contributing factors. OBJECTIVE: To identify how near-falls among older adults have been defined, reported, and monitored in the scientific literature. METHODS: Indexed literature published in English, Spanish, and Portuguese will be considered and retrieved from 10 databases, until August 31st, 2020. Two authors will independently screen titles, abstracts, and full texts against the eligibility criteria, and disagreements will be resolved by a third reviewer. This review will consider studies with different designs that have included older adults (aged 60 years and over), recruited participants from different settings, and had an explicit definition and/or reporting of near-falls. A customized form will be used to extract data from the included studies. The results will be presented in tabular form, accompanied by a narrative summary. This protocol is registered at https://osf.io/txnv4. EXPECTED RESULTS AND RELEVANCE: Depending on the results, a conceptual framework for nearfall reporting, contributing factors, and a possible prodrome of falls will also be presented. It is expected that the present study will help professionals identify and manage near-falls in different settings.

KEYWORDS: aging; accidental falls; preventive health services.

\footnotetext{
anniversidade de São Paulo - São Paulo (SP), Brazil.

bUniversity of Nottingham - Nottingham, United Kingdom.

university College London - London, United Kingdom.

dUniversity of Southampton - Southampton, United Kingdom.

eUniversidade Cidade de São Paulo - São Paulo (SP), Brazil.

fUniversidade Estadual de Campinas - Campinas (SP), Brazil.
}

Correspondence data: Ruth Caldeira de Melo - Universidade de São Paulo - Rua Arlindo Bettio, 1.000 - Vila Guaraciaba - CEP: 03828000 - São Paulo (SP), Brazil. E-mail: ruth.melo@usp.br @ruth_melo Received on: 10/26/2020. Accepted on: 03/30/2021

How to cite this article: Cervato CJ, Buarque GLA, Robinson K, Frost R, Gavin J, Perracini MR, et al. Defining, reporting, and monitoring near-falls in older adults: a scoping review protocol. Geriatr Gerontol Aging. 2021;15:e0210015. https://doi.org/10.5327/Z2447-212320212000129

https://doi.org/10.5327/22447-212320212000129 
INTRODUÇÃO: Além dos fatores de risco tradicionais para quedas (por exemplo, força muscular reduzida, polifarmácia e visão deficiente), pesquisadores têm investigado se outros fatores, como quase-quedas, podem ser identificados para permitir a intervenção e prevenção precoces. Uma quase-queda pode ser definida como um escorregão, um tropeço ou a perda de equilíbrio que resultaria em uma queda se os mecanismos de recuperação adequados não fossem ativados. Apesar do crescente interesse em quase-quedas, não há consenso sobre a definição, os métodos de registro e os fatores contribuintes. OBJETIVO: Identificar como as quase-quedas em idosos têm sido definidas, registradas e monitoradas na literatura científica. MÉTODOS: Será considerada a literatura indexada publicada em inglês, espanhol e português e extraída de 10 bases de dados, até 31 de agosto de 2020. Dois autores irão verificar os títulos, os resumos e os textos completos de forma independente de acordo com os critérios de elegibilidade, e as divergências serão resolvidas por um terceiro revisor. Nesta revisão, serão considerados estudos com diferentes desenhos que incluam idosos (com 60 anos ou mais), que tenham recrutado os participantes em diferentes ambientes e que tenham uma definição explícita e/ou registro de quase-quedas. Um formulário personalizado será utilizado para extrair os dados dos estudos incluídos. Os resultados serão apresentados em forma de tabela, acompanhados de um resumo narrativo. Este protocolo está registrado em https:// osf.io/txnv4. RESULTADOS ESPERADOS E RELEVÂNCIA: Dependendo dos resultados, também será apresentada uma matriz conceitual para o registro de quase-quedas, fatores contribuintes e um possível pródromo de quedas. Espera-se que o presente estudo ajude os profissionais na identificação e no gerenciamento de quase-quedas em diferentes cenários.

PALAVRAS-CHAVE: envelhecimento; acidentes por quedas; serviços preventivos de saúde.

\section{INTRODUCTION}

Falls can have significant consequences for public health as they can lead to hospitalization, increased health care needs, and even death. ${ }^{1}$ Furthermore, it is one of the main causes of admission to long-term care facilities that will pose a high demand on societies in coming years. ${ }^{2}$

Nearly $30 \%$ of community-dwelling older adults aged 65 years and over suffer a fall each year, ${ }^{3-6}$ and 30\%-50\% fall recurrently, ${ }^{7,8}$ with greater prevalence after 75 years of age. ${ }^{9,10}$ For institutionalized older adults, the prevalence of falls is twice as high compared to community-dwelling older adults. ${ }^{11-13}$ Greater accuracy in the reporting of falls and frail characteristics of residents might explain this increased prevalence of falls in long-term care facilities. ${ }^{14,15}$

The adoption of a clear definition is an important requirement when managing falls. Otherwise different interpretations among stakeholders can lead to misjudgments and to a lack of monitoring and poor reporting of fall events in clinical practice (i.e., adequate identification and management). ${ }^{16,17} \mathrm{~W}$ ithin the literature, several previous attempts have been made to define a fall event $\mathrm{t}^{17-20}$ and two points are common across the definitions:

- the fall event is unexpected and unintentional;

- the fall results in a change in body position to a lower level (e.g., resting on the floor/ground).

The Prevention of Falls Network Europe (ProFaNE) consensus group proposed that a fall should be defined as "an unexpected event in which the participants come to rest on the ground, floor, or lower level" 20 and also reinforced that slips or trips that result in the individual landing on the floor, ground, or lower surface also constitute a fall. ${ }^{20}$ Although falls have been extensively studied in previous decades, there are still different interpretations about what a fall is and its appropriate definition among older adults, professionals, and the scientific community, which in turn experiences difficulty in detecting falls early and in comparing empirical findings. ${ }^{16,21}$

Besides the well-known risk factors, some authors have also raised the importance of investigating other events that can establish a relationship with future falls, such as misplaced steps or near-falls. ${ }^{22-26}$ Different from the widespread concept about falls, a near-fall can be defined as a slip (sliding of the support leg), trip (impact of the swinging leg with an external object), or loss of balance where the person starts to fall but is able to recover the balance before landing on the floor or other lower surface. ${ }^{26-28}$ More recently, Maidan et al. ${ }^{24}$ proposed a new definition of near-fall, aiming to provide a more reliable tool for assessing fall risk in laboratory and community settings. The proposed definition is: "a stumble event or loss of balance that would result in a fall if sufficient recovery mechanisms were not activated". ${ }^{24}$ The authors also suggested that at least two of the following compensatory mechanisms should be activated to be determined as a near-fall: "(1) unplanned movement of arms or/and legs, (2) unplanned change in stride length, (3) lowering of the center of mass, (4) unplanned change in stride velocity, and (5) trunk tilt". ${ }^{24}$

In a prospective study, Nagai et al. ${ }^{22}$ asked participants to record the incidence of near-falls for 3 months. After this period, individuals were followed up for 6 months by telephone contact. In the initial 3 months, $40 \%$ of older adults 
experienced near-falls and $13 \%$ experienced substantial falls over 6 months. After adjusting for covariates, such as age, body mass index, sex, and physical frailty, the experience of a near-fall was positively related to the likelihood of falling in the future. Thus, self-report of near-falls may enhance the ability to discriminate older adults at risk before they have a first fall, which probably occurs among the youngest old. ${ }^{26,29}$

Therefore, seeking consensus definitions and standardized assessment parameters can corroborate a more targeted screening, enabling professionals and individuals themselves to identify and monitor these events more accurately in different settings and, in turn, allowing the development of more appropriate, early prevention strategies. Against this background, the objective of this scoping review is to identify how near-fall has been defined and reported by scientific studies. In addition, a framework for the reporting of near-falls in different settings will be developed. Depending on the results, factors contributing to near-falls and a discussion about the role of near-falls as a prodrome of future falls will also be presented.

\section{METHODS}

The present review will be conducted based on the Preferred Reporting Items for Systematic Reviews and Meta-Analyses Extension for Scoping Reviews (PRISMA-ScR) ${ }^{30}$ and previously published recommendations about scoping review methodology. ${ }^{31-34}$ As recommended, the present protocol was pre-registered with the Opens Science Framework (https:// osf.io/txnv4). The main steps adopted for this scoping review are summarized in the following subsections.

\section{Identifying the research question}

The review questions for this scoping review are:

- What terms have been used interchangeably with near-fall?;

- How has the term near-fall been defined in the scientific literature?;

- How does the scientific literature report and/or monitor near-falls?;

- Does the form of reporting and/or monitoring nearfalls vary among different settings?;

- What are the factors and outcomes associated with near-falls?;

- Are near-falls a predictor of falls?
The population, concept, and context (PCC) framework recommended by the Joanna Briggs Institute for scoping reviews will be used in this review to determine the research question and eligibility criteria. ${ }^{34}$

Studies that have defined and/or reported near-falls and related terms (i.e., slips, trips, and misplaced steps) [concept] will be considered for inclusion. In addition, the studies should clearly include older adults (aged 60 years and over) [population], independently of sex and presence of disease, who have been recruited from different settings (including community, primary care, health care centers, hospitals, and long-term care facilities) [context]. The present scoping review will also include synonymous terms for near-falls and older adults, as well as index terms when available. Studies that report the occurrence of near-falls will also be considered for analysis even if a clear definition of near-fall is not provided.

\section{Identifying relevant studies}

The search strategy of this scoping review has been developed to identify studies published in English, Spanish, and Portuguese languages from different sources of evidence (including observational, experimental, quantitative, or qualitative studies, systematic reviews, and study protocols). No publication date restrictions have been imposed in the searches. An initial search has been done in MEDLINE (PubMed) to analyze the words contained in titles and abstracts, and the index terms used to describe potentially eligible articles. A second search using all identified keywords and index terms has been done for all databases selected for the present study.

As near-falls are underexplored in the literature, all older age ranges will be included in the present review. It is important to note that the index term "aged" usually refers to persons 65 through 79 years of age (see an example at PubMed database: https://www.ncbi.nlm.nih.gov/mesh/68000368). So, in order not to restrict the searches to young older adults, the search line must also include index terms that cover 80 years of age and over (i.e., "Aged, 80 and over", see an example at PubMed database: https://www.ncbi.nlm.nih.gov/ mesh/68000369).

The final search string (Figure 1) has then been applied to the following databases: CINAHL, Cochrane Library, EMBASE, BVS/BIREME (Biblioteca Virtual em Saúde), MEDLINE (PubMed), AgeLine, SciELO (Scientific Electronic Library Online), Scopus, Web of Science, and

(“slipping” OR "tripping” OR "misplaced steps" OR "near-falls" OR "near-fall” OR "near falls" OR "near fall”)

AND (((Aged OR Elderly) OR ("Aged, 80 and over" OR "Oldest Old" OR Nonagenarians OR Nonagenarian

OR Octogenarians OR Octogenarian OR Centenarians OR Centenarian)) OR (“Old People” OR “Old Adults”))

Figure 1. Final search string. 
PROQUEST (Appendix 1, available at https://osf.io/kthg8/). The entire search process will be conducted with the support of an experienced librarian.

\section{Selecting the studies}

The studies retrieved from all databases will be imported to Rayyan software (https://rayyan.qcri.org/welcome), where the selection process will be conducted by the research team. After removing duplicates, two authors from the research team will screen the remaining studies against the inclusion criteria based on title and abstract. If they disagree, a third author will be consulted. For a more detailed analysis, two authors will read the selected studies in full, and any discrepancies will be resolved by consensus between them.

The inclusion criteria for the present review follows the "PCC" mnemonic, which is recommended as a guide for scoping reviews. Studies will be considered if they:

- include older adults aged 60 years and over, independently of sex and associated conditions [population];

- have defined and/or reported near-falls or a similar concept (i.e., slipping, tripping, and misplaced steps) [concept].

Because some low- and middle-income countries consider persons aged 60 years and over to be at an old age, the age range in the present study will be set at this mark, instead of 65 years of age and over (age range more commonly used in high-income countries). No restriction will be applied to the settings (context) of participants' recruitment. Studies with different research designs (observational, experimental, quantitative, or qualitative studies, systematic reviews, and study protocols) will be considered in the present scoping review. The studies will be excluded if they:

- have not been fully published in the selected languages described above;

- have been published only as an abstract;

- have not been peer-reviewed (i.e., gray literature will not be considered in the present review).

Case reports, letters to the editor, commentaries, and opinion papers will also be excluded. The reference lists of all studies selected for inclusion will be reviewed for additional studies.

\section{Charting the data}

Two independent reviewers will extract data relevant to this review from the included studies using the methods recommended by Peters et al. ${ }^{34}$ Data extraction will include: author(s), year of publication, article title, source (journal, volume, issue, page numbers), study design, aims, sample size, recruitment setting, population characteristics (mean age, sex, specific diseases), methodology/methods, explicit definition of near-fall, tools used to report/monitor near-falls, factors and outcomes associated with near-falls, and principal results/findings/recommendations (Appendix 2, available at https://osf.io/kthg8/). The data extraction form will be piloted in five studies and modified as necessary during the data extraction process.

\section{Collating, summarizing, and reporting the results}

The review decision process will be presented in a flowchart, including the results from the search, removal of duplicate citations, phases of study selection (title/abstract and full text), reasons for excluding papers after full-text reading, and final number of included studies. In order to illustrate this process, a PRISMA flowchart will be used..$^{30,35}$

The results will be presented in tabular form, accompanied by a narrative summary related to the objective of the present scoping review. A data presentation table will be developed based on the extracted data, grouped according to study design. Depending on the results, a framework for the identification of near-falls in different settings will be developed and factors contributing to near-falls will also be presented.

\section{Relevance and dissemination}

The present scoping review has the potential to inform and help health care professionals and researchers on how near-falls could be defined, reported, and monitored in different settings. The identification of factors potentially associated with near-falls could contribute to the development of early prevention strategies for older adults before their first fall. Results will also help to guide future studies, such as clinical trials. The complete scoping review will be disseminated through presentations at conferences on aging and publication in an international peer-reviewed journal.

\section{ACKNOWLEDGEMENTS}

The authors gratefully acknowledge the contribution of librarian Ana Paula Morais e Oliveira from the Universidade Estadual de Campinas (Brazil) for the specialized support during the search process.

\section{CONFLICTS OF INTEREST}

The authors declare no conflict of interest. 


\section{FUNDING}

This study was supported in part by the Coordenação de Aperfeiçoamento de Pessoal de Nível Superior - Brasil (CAPES) - Finance Code 001.

\section{AUTHORS' CONTRIBUTION}

CJC: conceptualization, investigation, methodology, project administration, writing — original draft, writing — review
\& editing. GLAB: investigation, methodology, writing review \& editing. KR: investigation, methodology, writing - review \& editing. RF: investigation, methodology, writing - review \& editing. JG: investigation, methodology, writing - review \& editing. MRP: conceptualization, methodology, writing — original draft, writing — review \& editing. RCM: conceptualization, investigation, methodology, project administration, supervision, writing — original draft, writing — review \& editing.

\section{REFERENCES}

1. Abreu DOM, Novaes ES, Oliveira RR, Mathias TAF, Marcon SS. Fall-related Admission and Mortality in Older Adults in Brazil: Trend Analysis. Ciên Saúde Colet [electronic journal]. 2018 [cited on 2020 May 26];23(4):1131-41. Available in: https://pubmed. ncbi.nlm.nih.gov/29694573/ https://doi.org/10.1590/141381232018234.09962016

2. Gill TM, Murphy TE, Gahbauer EA, Allore HG. Association of injurious falls with disability outcomes and nursing home admissions in community-living older persons. Am J Epidemiol [electronic journal]. 2013 [cited on 2020 Jun 1];178(3):418-25. Available in: https://doi. org/10.1093/aje/kws554

3. Milat AJ, Watson WL, Monger C, Barr M, Giffin M, Reid M. Prevalence, circumstances and consequences of falls among community-dwelling older people: results of the 2009 NSW Falls Prevention Baseline Survey. N S W Public Health Bull [electronic journal]. 2011 [cited on 2020 May 26];22(3-4):43-8. Available in: http://dx.doi.org/10.1071/ NB10065

4. Ambrose AF, Paul G, Hausdorff JM. Risk factors for falls among older adults: a review of the literature. Maturitas [electronic journal]. 2013 [cited on 2020 May 28];75(1):51-61. Available in: http://dx.doi. org/10.1016/j.maturitas.2013.02.009

5. Rodríguez-Molinero A, Narvaiza L, Gálvez-Barrón C, de la Cruz JJ, Ruíz J, Gonzalo N, et al. Falls in the Spanish elderly population: Incidence, consequences and risk factors. Rev Esp Geriatr Gerontol [electronic journal]. 2015 [cited on 2020 Jan 10];50(6):274-80. Available in: http://dx.doi.org/10.1016/j.regg.2015.05.005

6. Elias Filho J, Borel WP, Diz JBM, Barbosa AWC, Britto RR, Felício DC. Prevalence of falls and associated factors in communitydwelling older Brazilians: a systematic review and meta-analysis. Cad Saude Publica [electronic journal]. 2019 [cited on 2020 May 8];35(8):e00115718. Available in: http://dx.doi.org/10.1590/0102$311 \times 00115718$

7. Perracini MR, Ramos LR. Fall-related factors in a cohort of elderly community residents. Rev Saude Publica [electronic journal]. 2002 [cited on $2020 \mathrm{Apr} 20$ ];36(6):709-16. Available in: http://dx.doi. org/10.1590/s0034-89102002000700008

8. Lavedán A, Viladrosa M, Jürschik P, Botigué T, Nuín C, Masot O, et al. Fear of falling in community-dwelling older adults: A cause of falls, a consequence, or both? PLoS One [electronic journal]. 2018 [cited on 2019 Nov 22];13(5):e0197792. Available in: http://dx.doi. org/10.1371/journal.pone.0194967

9. Nunes BP, de Oliveira Saes M, Siqueira FV, Tomasi E, Silva SM, da Silveira DS, et al. Falls and self-assessment of eyesight among elderly people: a population-based study in a south Brazilian municipality. Arch Gerontol Geriatr [electronic journal]. 2014 [cited on 2019 Dec 10];59(1):131-5. Available in: http://dx.doi.org/10.1016/j. archger.2014.03.004

10. Cruz DT da, Ribeiro LC, Vieira M de T, Teixeira MTB, Bastos RR, Leite ICG. Prevalence of falls and associated factors in elderly individuals. Rev Saude Publica [electronic journal]. 2012 [cited on 2020 Jun 6];46(1):138-46. Available in: http://dx.doi.org/10.1590/ s0034-89102011005000087
11. Rosendahl E, Lundin-Olsson L, Kallin K, Jensen J, Gustafson Y, Nyberg L. Prediction of falls among older people in residential care facilities by the Downton index. Aging Clin Exp Res [electronic journal]. 2003 [cited on 2020 Jun 22];15(2):142-7. Available in: http://dx.doi. org/10.1007/bf03324492

12. Meyer G, Köpke S, Haastert B, Mühlhauser I. Comparison of a fall risk assessment tool with nurses' judgement alone: a cluster-randomised controlled trial. Age Ageing [electronic journal]. 2009 [cited on 2020 Jun 19];38(4):417-23. Available in: http://dx.doi.org/10.1093/ageing/ afp049

13. Lannering C, Ernsth Bravell M, Midlöv P, Östgren C-J, Mölstad S Factors related to falls, weight-loss and pressure ulcers--more insight in risk assessment among nursing home residents. I Clin Nurs [electronic journal]. 2016 [cited on 2019 Nov 20];25(7-8):94050. Available in: http://dx.doi.org/10.1111/jocn.13154

14. Rubenstein LZ, Josephson KR. The epidemiology of falls and syncope. Clin Geriatr Med [electronic journal]. 2002 [cited on 2020 Mar 15];18(2):141-58. Available in: https://linkinghub.elsevier.com/ retrieve/pii/S0749069002000022 https://doi.org/10.1016/S07490690(02)00002-2

15. Aranda-Gallardo M, Morales-Asencio JM, Enriquez de LunaRodriguez M, Vazquez-Blanco MJ, Morilla-Herrera JC, Rivas-Ruiz $\mathrm{F}$, et al. Characteristics, consequences and prevention of falls in institutionalised older adults in the province of Malaga (Spain): a prospective, cohort, multicentre study. BMJ Open [electronic journal]. 2018 [cited on 2020 Mar 15];8(2):e020039. Available in: http:// dx.doi.org/10.1136/bmjopen-2017-020039

16. Zecevic AA, Salmoni AW, Speechley M, Vandervoort AA. Defining a fall and reasons for falling: comparisons among the views of seniors, health care providers, and the research literature. Gerontologist [electronic journal]. 2006 [cited on 2020 Feb 1];46(3):367-76. Available in: http://dx.doi.org/10.1093/geront/46.3.367

17. World Health Organization. WHO Global Report on Falls Prevention in Older Age [Internet]. World Health Organization; 2008. Available from: https://books.google.com/books/about/WHO_Global_Report on_Falls_Prevention_i.html?hl=\&id=ms9o2dvfaQk̄C. Accessed on Apr 19, 2020.

18. The Prevention of Falls in Later Life: A Report of the Kellogg International Work Group on the Prevention of Falls by the Elderly. Dan Med Bull. 1987;34 (Suppl. 4):1-24.

19. Buchner DM, Hornbrook MC, Kutner NG, Tinetti ME, Dry MG, Mulrow CD, et al. Development of the common data base for the FICSIT trials. J Am Geriatr Soc [electronic journal]. 1993 [cited on 2019 Oct 17];41(3):297-308. Available in: http://dx.doi. org/10.1111/j.1532-5415.1993.tb06708.x

20. Lamb SE, Jørstad-Stein EC, Hauer K, Becker C, Prevention of Falls Network Europe and Outcomes Consensus Group. Development of a common outcome data set for fall injury prevention trials: the Prevention of Falls Network Europe consensus. J Am Geriatr Soc [electronic journal]. 2005 [cited on 2019 Oct 15];53(9):1618-22. Available in: http://dx.doi. org/10.1111/j.1532-5415.2005.53455.x 
21. Hauer K, Lamb SE, Jorstad EC, Todd C, Becker C, PROFANE-Group. Systematic review of definitions and methods of measuring falls in randomised controlled fall prevention trials. Age Ageing [electronic journal]. 2006 [cited on 2019 Oct 20];35(1):5-10. Available in: http:// dx.doi.org/10.1093/ageing/afi218

22. Nagai K, Yamada M, Komatsu M, Tamaki A, Kanai M, Miyamoto T, et al. Near falls predict substantial falls in older adults: A prospective cohort study. Geriatr Gerontol Int [electronic journal]. 2017 [cited on 2020 Jan 14];17(10):1477-80. Available in: http://dx.doi.org/10.1111/ ggi.12898

23. Stack E, Ashburn A. Fall events described by people with Parkinson's disease: implications for clinical interviewing and the research agenda. Physiother Res Int [electronic journal]. 1999 [cited on 2020 May 5];4(3):190-200. Available in: http://dx.doi.org/10.1002/pri.165

24. Maidan I, Freedman T, Tzemah R, Giladi N, Mirelman A, Hausdorff $J M$. Introducing a new definition of a near fall: intra-rater and interrater reliability. Gait Posture [electronic journal]. 2014 [cited on 2020 Jan 21];39(1):645-7. Available in: http://dx.doi.org/10.1016/j. gaitpost.2013.07.123

25. Weiss A, Shimkin I, Giladi N, Hausdorff JM. Automated detection of near falls: algorithm development and preliminary results. BMC Res Notes [electronic journal]. 2010 [cited on 2020 Mar 19];3:62. Available in: http://dx.doi.org/10.1186/1756-0500-3-62

26. Srygley JM, Herman T, Giladi N, Hausdorff JM. Self-report of missteps in older adults: a valid proxy of fall risk? Arch Phys Med Rehabil [electronic journal]. 2009 [cited on 2020 Apr 26];90(5):786-92. Available in: http://dx.doi.org/10.1016/j.apmr.2008.11.007

27. Ryan JW, Dinkel JL, Petrucci K. Near falls incidence. A study of older adults in the community. J Gerontol Nurs [electronic journal]. 1993 [cited on 2020 May 7];19(12):23-8. Available in: https://doi. org/10.3928/0098-9134-19931201-06

28. Pang I, Okubo Y, Sturnieks D, Lord SR, Brodie MA. Detection of Near Falls Using Wearable Devices: A Systematic Review. J Geriatr Phys
Ther [electronic journal]. 2019 [cited on 2020 Apr 20];42(1):48-56. Available in: http://dx.doi.org/10.1519/JPT.0000000000000181

29. Deschamps T, Le Goff CG, Berrut G, Cornu C, Mignardot J. A decision model to predict the risk of the first fall onset. Exp Gerontol [electronic journal]. 2016 [cited on 2021 Feb 1];81:51-5. Available in: http:// dx.doi.org/10.1016/j.exger.2016.04.016

30. Tricco AC, Lillie E, Zarin W, O'Brien KK, Colquhoun H, Levac D, et al. PRISMA Extension for Scoping Reviews (PRISMA-ScR): Checklist and Explanation. Ann Intern Med [electronic journal]. 2018 [cited on 2019 Jul 20]; 169(7):467-73. Available in: http://dx.doi.org/10.7326/ M18-0850

31. Arksey H, O'Malley L. Scoping studies: towards a methodological framework. Int J Soc Res Methodol [electronic journal]. 2005 [cited on 2019 Oct 26];8(1):19-32. Available in: http://www.tandfonline. com/doi/abs/10.1080/1364557032000119616

32. Levac D, Colquhoun H, O'Brien KK. Scoping studies: advancing the methodology. Implement Sci [electronic journal]. 2010 [cited on 2019 Jul 10];5:69. Available in: http://dx.doi.org/10.1186/1748-5908-5-69

33. Colquhoun HL, Levac D, O’Brien KK, Straus S, Tricco AC, Perrier $L$, et al. Scoping reviews: time for clarity in definition, methods, and reporting. J Clin Epidemiol [electronic journal]. 2014 [cited on 2019 Oct 5];67(12):1291-4. Available in: http://dx.doi.org/10.1016/j. jclinepi.2014.03.013

34. Peters MDJ, Marnie C, Tricco AC, Pollock D, Munn Z, Alexander L, et al. Updated methodological guidance for the conduct of scoping reviews. JBI Evid Synth [electronic journal]. 2020 [cited on 2019 Oct 20];18(10):2119-26. Available in: http://dx.doi.org/10.11124/ JBIES-20-00167

35. Moher D, Liberati A, Tetzlaff J, Altman DG, PRISMA Group. Preferred reporting items for systematic reviews and meta-analyses: the PRISMA statement. PLoS Med [electronic journal]. 2009 [cited on 2019 Oct 19];6(7):e1000097. Available in: http://dx.doi.org/10.1371/ journal.pmed.1000097 